\title{
Chega de Corrupção: Como os Programas de Governo dos Candidatos à Presidência da República em 2018 Abordaram o Tema
}

\author{
No More Corruption: How the Government Programs of Candidates for the Presidency of \\ the Republic in 2018 Addressed the Theme
}

\author{
Fernando Gustavo da Silva Quirino' \\ Lívia Maria de Pádua Ribeiro ${ }^{2}$ \\ Amanda Fontes Silva ${ }^{3}$ \\ Gabriel Augusto de Carvalho ${ }^{4}$
}

\begin{abstract}
Resumo
Nos últimos anos, o combate à corrupção ganhou relevância no debate nacional a partir de denúncias no cerne do poder em âmbito federal. Nesse sentido, questiona-se como a corrupção foi abordada nos programas de governo dos candidatos ao cargo de presidente da República Federativa do Brasil em 2018. Assim, o presente estudo consiste na análise de conteúdo, aplicada aos programas de governo dos candidatos ao cargo em 2018, na temática considerada. Como embasamento teórico, foram apresentadas reflexões acerca do institucionalismo, com maior ênfase na concepção de isomorfismo, partindo para o conceito da corrupção e as abordagens acadêmicas para a resolução dessas ações. O corpus da pesquisa consiste nos programas de governo apresentados no Tribunal Superior Eleitoral no momento da homologação das candidaturas. A análise foi desenvolvida com a apoio do software ATLAS.TI $囚$, em sua versão 7.5.16. O estudo conclui que, embora a temática corrupção tenha ganhado relevância no debate nacional nos últimos anos, ainda não existe um consenso claro no campo político quanto às medidas de combate a ações corruptas no setor público.
\end{abstract}

Palavras-chave: corrupção. eleições. análise de conteúdo. programas de governo.

\begin{abstract}
In recent years, the fight against corruption has gained relevance in the national debate based on denunciations at the heart of power at the federal level. In this sense, it is questioned how corruption was addressed in the government programs of candidates for the post of president of the Federative Republic of Brazil in 2018. Thus, the present study consists of content analysis, applied to the government programs of candidates for the post in 2018, on the subject considered. As a theoretical basis, reflections on institutionalism were presented, with a greater emphasis on the concept of isomorphism, starting with the concept of corruption and academic approaches to the resolution of these actions. The corpus of the research consists of the government programs presented at the Superior Electoral Court at the time of the approval of the candidacies. The analysis was developed with the support of the software ATLAS.TI尺, in 7.5.16 version. The study concludes that, although corruption has gained relevance in the national debate in recent years, there is still no clear consensus in the political field regarding measures to combat corrupt actions in the public sector.
\end{abstract}

Keywords: corruption. elections. content analysis. government programs.

Mestre em Administração pelo Centro Federal de Educação Tecnológica de Minas Gerais (CEFET-MG). Especialista em Gestão Estratégica pela Fundação João Pinheiro. do Centro Federal de Educação Tecnológica de Minas Gerais (CEFET-MG). 


\section{Introdução}

O que tornam as organizações tão semelhantes? Partindo dessa indagação, DiMaggio e Powell (1983) chegaram à conclusão de que os mecanismos de racionalização e burocratização passaram do mercado competitivo para o Estado e para as profissões, resultando em organizações homogêneas, mas sem, necessariamente, torná-las mais eficientes. O nome dado a essa tendência é o isomorfismo. Segundo Hawley (1968), este é um processo de restrição que força uma unidade em uma população a se assemelhar a outras unidades que enfrentam o mesmo conjunto de condições ambientais.

No âmbito político brasileiro, entende-se que a herança deixada pelo processo de colonização no país tornou o problema da corrupção uma instituição enraizada na sociedade e no estado (LOPES, 2014) e que é percebido pela população como algo persistente e inerente a qualquer pessoa que ocupe um cargo no poder público do país, ou seja, trata-se de uma conduta entendida como homogênea, porém ineficiente. No entendimento de Johnston (2002), a corrupção é uma atividade praticada por pessoas e grupos reais que traficam influências em um dado ambiente de oportunidades, de recursos e limitações, e afetam diretamente na natureza e continuidade do desenvolvimento das sociedades em que ocorrem.

Nesse sentido, Freitas Junior e Medeiros (2018) apontam três processos que podem regular e perenizar a corrupção nas organizações: a institucionalização, racionalização e socialização, considerando uma atuação conjunta desses processos. Bonzo e Honório (2005) afirmam que essas condições fazem com que as organizações sejam guiadas por valores legitimados institucionalmente para aumentar a probabilidade de sobrevivência. A institucionalização ocorre quando as práticas de corrupção são admitidas como parte da rotina (FREITAS JUNIOR; MEDEIROS, 2018). Embora o isomorfismo tenha atingido o Estado (DIMAGGIO; POWELL, 1983), a corrupção, frequentemente noticiada no Brasil, desperta na população a expectativa por mudanças no cenário político a partir do momento em que um novo ciclo eleitoral se inicia.

Para Lopes (2014), ainda que a corrupção não ocorra exclusivamente no Brasil, é passível de compreensão que haja um esforço por parte da opinião pública e dos meios de comunicação nacional para noticiar os casos de escândalos envolvendo políticos e cidadãos brasileiros. O autor justifica que esse esforço tem relação com o espanto causado pela naturalidade com a qual os envolvidos respondem ao processo, pela complacência da sociedade em relação ao problema, pela dificuldade em apurar e definir culpados, e pelo desvio de verbas que poderiam melhorar as condições de vida da população e impulsionar o desenvolvimento econômico do país.

No ranking dos países menos corruptos para os mais corruptos, o Brasil ocupa o $106^{\circ}$ lugar entre os 180 analisados, com 35 pontos, a mesma pontuação de países como Egito, Costa do Marfim, Albânia, Argélia, Mongólia e Macedônia do Norte. O primeiro colocado é a Dinamarca, com 87 pontos, com a mesma pontuação da Nova Zelândia, ficando à frente apenas por critério de ordem alfabética (TRANSPARENCY INTERNATIONAL, 2019). Esse levantamento, de 2019, é resultado de um projeto da Universidade de Gottinges e incorporado pela Transparência Internacional com o objetivo de impedir o abuso de poder, suborno e acordos secretos. Uma das formas encontradas foi criar um índice que classifica os países por meios de notas, que variam de absolutamente corrupto (0) até absolutamente íntegro (10), como meio de expor os países que mais cometem ações fraudulentas.

Apesar da preocupação a respeito da corrupção, Silva (1994) destaca que os estudos sobre a temática começaram a ganhar força a partir da década de 80 em decorrência do período político da época (1964-84). Segundo Freitas Junior e Medeiros (2018), a sucessão de escândalos de corrupção nas mais diferentes esferas da administração pública e privada, a partir da promulgação da Constituição de 1988, também influenciou no aumento no interesse sobre o tema corrupção. Antes disso, durante o período militar, houve grande censura da mídia, que privou a população de ter acesso a informações reais a respeito da política do país. Aqueles que ousavam burlar o sistema eram fortemente reprimidos. Tal realidade contribuiu para que os estudos sobre corrupção na época fossem praticamente inexistentes.

Ressalta-se que a participação da sociedade civil se faz necessária para combater a corrupção, principalmente por meio da avaliação de programas públicos e denúncias de abusos de poder, irregularidades na administração e práticas corruptas (GROSSI; PIANEZZI, 2016). Desde 2011, o Brasil conta com a Lei de Acesso à Informação (BRASIL, 2011), que determina o nível de acesso dos cidadãos a informações de governo, com classificação dos documentos de acordo com o grau de sigilo. Essa legislação impõe aos entes da federação a obrigação de dar resposta imediata aos pedidos de informação do cidadão, estabelecendo um prazo máximo de 20 dias para resposta, prorrogáveis por mais 10. Os órgãos e entidades públicas receberam o prazo de 180 dias para se adequarem à lei a partir de sua publicação (novembro/2011), inclusive colocando em seus sítios eletrônicos campos para que o cidadão faça seus requerimentos.

Assim como a participação civil é importante para o combate à corrupção, a atuação dos políticos, principalmente do presidente, também é determinante. Posto o contexto, apresenta-se o seguinte questionamento: como a corrupção foi abordada nos programas de governo dos candidatos ao cargo de presidente da República Federativa do Brasil em 2018?

Para cumprir o objetivo de compreender como a corrupção foi abordada nos programas de governo dos candidatos ao cargo de presidente em 2018, este estudo se inicia a partir do referencial teórico e do levantamento dos conceitos sobre institucionalismo, corrupção, seguida da metodologia utilizada. Nesse sentido, são apresentados os procedimentos metodológicos utilizados para a realização desta pesquisa, o que inclui a natureza e a estratégia 
da investigação, bem como os procedimentos de coleta e análise de dados utilizados. Por fim, segue-se a análise dos resultados da pesquisa, complementados pelas conclusões encontradas neste estudo.

\section{Referencial Teórico}

Dado o objetivo deste estudo, o referencial teórico está estruturado em duas subseções. No primeiro momento, é apresentada a teoria do institucionalismo, sendo ressaltada a influência que as instituições podem exercer no comportamento dos agentes, e sua relação com a corrupção. Posteriormente, é definido o conceito de corrupção adotado neste estudo e são destacados estudos que exploram o tema.

\subsection{Institucionalismo}

Com origem nas ciências sociais, a teoria institucional emergiu no final do século XIX, como uma das abordagens mais promissoras, juntamente com as perspectivas ecológica e de redes, para explicar o funcionamento e evolução da sociedade organizacional. Essa teoria é caracterizada como o estudo dos processos dinâmicos e da evolução cultural, negando-se a ser uma teoria econômica da eficiência estática e do equilíbrio de mercado (CARVALHO, VIEIRA; GOULART, 2005).

Segundo Zucker (1987), boa parte do arcabouço teórico do institucionalismo ressalta o fato de que as organizações são influenciadas por pressões normativas que podem se originar tanto de fontes externas, como o Estado, quanto de fontes internas à própria organização. De acordo com Bonzo e Honório (2005), tais pressões fazem com que a empresa seja guiada por valores legitimados institucionalmente. A adoção de tais elementos, legitimados conforme o ambiente institucional, aumenta a probabilidade de sobrevivência da organização.

A teoria institucional é explorada por diversas vertentes, como a política, a econômica e a sociológica. No âmbito político, a perspectiva institucional concentra seu interesse na autonomia relativa das instituições políticas ante a sociedade, na complexidade dos sistemas políticos e na centralidade da representação e do simbolismo no universo político (CHANLAT, 1989).

Por se tratar de uma teoria que compreende apenas as questões comportamentais do indivíduo, tais como os votos, formação de partidos e opinião pública, e também pelo desinteresse das estruturas institucionais de comportamento político, a perspectiva institucional perdeu sua força (SCOTT, 1995). Em meados da década de 70, tal perspectiva voltou a ganhar destaque por tratar de questões como autonomia das instituições políticas frente à sociedade, bem como a complexidade dos sistemas políticos e sua representação e simbolismo no que tange à abordagem política (CARVALHO, VIEIRA; GOULART 2005).

Já a abordagem econômica surgiu a partir de um artigo feito por Veblen, em 1998, com críticas à escola clássica. Segundo Carvalho, Vieira e Goulart (2005), os clássicos consideravam o homo economicus fator determinante para o desenvolvimento do sistema econômico, enquanto a nova concepção considerava que a abordagem econômica institucional sustentava os costumes e que as convenções determinam o comportamento econômico.

Em relação ao institucionalismo sociológico, esse aborda que a relação dos atores sociais com a sociedade não é apenas instrumental, mas também interpretativa (HALL; TAYLOR, 1996). Sendo assim, essa vertente do institucionalismo traz à tona a questão da legitimidade, pois, para os autores que adotam essa linha teórica, a própria emergência de instituições é considerada um processo de legitimação (ANDREWS, 2005).

Conforme afirma Pessoa (2008), a teoria institucional também investiga questões referentes à estrutura e ao agente com o intuito de entender como uma instituição molda o comportamento humano e se ela é dependente da disposição dos agentes em comportar-se como tal. Entretanto a teoria perdeu sua força para a escola neoclássica, mesmo sendo a linha dominante de pensamento econômico norte-americano. Hodgson (1994) defende que essa perda de espaço se deu pelo seu afastamento da consolidação teórica e conceitual, e afirma ainda que excessiva atenção ao empirismo terminou por caracterizar os estudos institucionalistas como ingênuos e teoricamente frágeis e seus pesquisadores como "colecionadores de dados por excelência".

Carvalho, Vieira e Goulart (2005) também chamam a atenção para o declínio da análise institucional da economia. Segundo os autores, a teoria acabou por ser engolida pela análise econômica ortodoxa, isolando o processo econômico das demais instituições sociais e políticas, ou seja, da própria estrutura social. Nos anos iniciais de um negócio, a empresa tende a adotar sua própria forma de gerenciamento, abordagem e ferramentas. Todavia, com o passar do tempo, essas organizações acabam se adaptando ao ambiente e assumem uma estrutura homogênea, ou seja, se tornam isomórficas e passam a atuar de forma semelhante às demais.

De acordo com DiMaggio e Powell (2005), o isomorfismo na esfera populacional sugere que as características organizacionais são modificadas na direção de uma compatibilidade crescente com as características do ambiente. Fatores como o número de organizações em uma população e a diversidade de configurações organizacionais são, segundo os autores, isomórficas à diversidade ambiental.

Existem ainda três mecanismos por meio dos quais ocorrem mudanças isomórficas, visto que cada um desses mecanismos possui seus próprios antecedentes, todavia os três tipos podem derivar de condições diferentes e levar 
a resultados distintos. São eles: "1) isomorfismo coercitivo, que deriva de influências políticas e do problema de legitimidade; 2) isomorfismo mimético, que resulta de respostas padronizadas à incerteza; e 3) isomorfismo normativo, associado à profissionalização" (DIMAGGIO; POWELL, 2005, p. 4).

Essa realidade das organizações atuais nos remete à gaiola de ferro, que é uma expressão utilizada por Max Weber para "condenar" a sociedade em que vivemos e que aprisiona a humanidade. Segundo DiMaggio e Powell (2005), Weber afirma que a burocracia constituía um meio tão eficiente e poderoso de controlar homens e mulheres que, uma vez estabelecido, o momentum da burocratização seria irreversível (WEBER, 1968).

Conforme a concepção de Rosa (2008), na realidade da gaiola de ferro, mesmo com a possibilidade de nos movermos lateralmente, coexiste uma gaiola que priva o indivíduo ou uma organização de uma plena autonomia. Quirino et. al. (2018) enfatizam que essa identidade isomórfica fica evidenciada de forma mais ampla, inclusive nas manifestações culturais de uma sociedade. Nesse mote, a seção a seguir trata de forma sintética a temática corrupção, em suas abordagens e significados na Academia.

\subsection{Corrupção}

Do latim "corrumpere", que significa destruir ou adulterar (GROSSI; PIANEZZI, 2016), a corrupção é um termo que gera controvérsias. A explicação de Brei (1996) para os diferentes pontos de vista entre os autores que estudam o tema está na falta de consenso quanto à conceituação do que seja uma ação corrupta e pela diversidade de atos que estão associadas ao termo corrupção: trapaça, velhacaria, logro, ganho ilícito, desfalque, concussão, falsificação, espólio, fraude, suborno, peculato, extorsão, nepotismo e outros. Brei (1996) ainda observa que as definições de corrupção deixam o impacto ético do fenômeno de lado para focar no mercado. Dessa forma, a falta de abordagem sobre a responsabilidade e justiça, lealdade profissional e organizacional e o conjunto de valores político-sociais tornam as definições deficientes e unilaterais.

Nesse trabalho, adota-se a definição de Silva (1994, p.21), que afirma que a corrupção é "uma espécie de desvio de um padrão de conduta institucionalizado que se caracteriza principalmente pela utilização do público pelo privado com um manifesto propósito desfavorecimento pessoal ou grupal". De forma mais resumida, Schleifer e Vishny (1993) descrevem a corrupção governamental como o uso de propriedades governamentais por parte de agentes públicos para ganhos pessoais. Para Abed e Davoodi (2000), a corrupção é atribuída, em grande parte, como um sintoma de falta de atenção nas estruturas e instituições econômicas, considerada a origem do que é percebido como corrupção no setor público. Filgueiras (2008) ainda destaca que a corrupção emerge com incentivos que culminam com propina e suborno para a elevação da utilidade dos agentes.

Rose-Ackerman (1999) retrata a abordagem econômica da corrupção, que é um sintoma de problemas na gestão do Estado, sendo as instituições, construídas para a gestão pública, utilizadas para a obtenção de enriquecimento e de outros benefícios pessoais. Nessa perspectiva, a corrupção é fruto da ação autointeressada dos agentes econômicos, que, devido à sua racionalidade, priorizam a obtenção de uma maior utilidade ao satisfazerem suas preferências individuais (FILGUEIRAS, 2008). Todavia Abed e Davoodi (2000) afirmam que a corrupção não é exclusivamente um fenômeno econômico. Ela se manifesta também nos processos políticos, no sistema judiciário e outras esferas, apesar de despertar maior interesse na esfera econômica devido ao enfraquecimento que a corrupção na política pública causa na capacidade do Estado de realizar suas funções designadas nesse âmbito.

Ao analisarem a relação entre o escopo de atividades estatais e a democracia sobre a ocorrência de corrupção, Kotera, Okada e Samreth (2012) concluem que, em países com pouca tradição democrática, o aumento no tamanho do governo pode agravar a corrupção, já que o governo possui dificuldades no monitoramento. Por outro lado, quando uma democracia é suficientemente consolidada, o aumento de atribuições do governo produz redução nos índices de corrupção, o que se explica por mecanismos eficientes de monitoramento, capazes de conter a corrupção conduzida pelos políticos e burocratas.

Diversos autores têm procurado compreender a origem da corrupção por parte de agentes públicos. Nesse mote, Schleifer e Vishny (1993) apontam que um governo menos centralizado permite uma atuação mais livre do agente governamental, o que abre espaço para a cobrança de propinas, pois, dada a necessidade de atender às demandas de diversos braços operacionais do governo (ministérios, secretarias, agências reguladoras etc.), é possível que em cada um desses existam agentes corruptos. Outro ponto colocado no mesmo estudo envolve o caráter de sigilo de algumas operações que o governo faz. Quanto mais sigiloso (portanto, menos transparente), maior a possibilidade de uma corrupção também sigilosa e confortável para os praticantes.

Dentro de outra perspectiva, Huntington (1975) expõe que a corrupção se origina de modo mais vigoroso em sociedades que experimentam um crescimento econômico que não é acompanhado de avanços no plano institucional e político. Matías-Pereira (2018) avalia que o perfil individual do gestor público ganha destaque, no sentido que ele possui um papelchave no combate aos desvios comportamentais no setor público, entretanto ainda persiste no Brasil a indicação de agentes públicos por critério político, colocando a questão do mérito em segundo plano.

Destaca Brei (1996) que "diferentes pessoas percebem a corrupção diferentemente" (p.73). Nesse sentido, conceitualmente, algumas práticas podem não ser efetivamente categóricas quanto à classificação como ato corrupto 
ou não, e até mesmo o grau de gravidade de uma ação específica. O autor ainda destaca o papel central da metodologia nos estudos sociais, com o intuito de distanciar a pesquisa da subjetividade do pesquisador.

É válido enfatizar que a percepção da corrupção deve ser trabalhada com parcimônia, dado que "a opinião das pessoas é demasiadamente influenciada pelo noticiário" (ABRAMO, 2005, p. 36), ou seja, a divulgação de notícias sobre corrupção aumentam a percepção de corrupção, ainda que o fato possa demonstrar uma melhoria na estrutura de combate à corrupção. Abramo (2005) enfatiza que, de forma equivocada, alguns governos trabalham com a questão da corrupção baseados apenas em campanha publicitária, o que não produz sozinho a redução dos desvios.

Conforme apontam Sargiacomo et al. (2015, p. 96), as "assembléias anticorrupção podem ser eternamente otimistas, mas perpetuamente fracassadas". Para Grossi e Pianezzi (2016), essa afirmação remete a leis anticorrupção que apresentam natureza simbólica, pois, apesar de haver uma estrutura institucional e legal de combate à corrupção, a fiscalização é apenas esporádica, as regras são demasiadamente complexas e os processos judiciais são demorados. No que tange ao combate à corrupção, Oliveira Júnior, Costa e Mendes (2014) evidenciam que, para o neo-institucionalismo, são necessárias reformas institucionais. Por meio dessas reformas devem ser priorizadas ações que reduzam a discricionariedade na tomada de decisão dos agentes, aumentem a transparência e, por fim, elevem as punições para os corruptos, de modo a tornar maiores os custos de suas ações.

De forma geral, as estratégias anticorrupção têm empregado uma combinação de ações diretas contra o comportamento corrupto, enquanto buscam reformas de políticas e instituições e são classificadas de acordo com três abordagens. A primeira destina-se a aumentar a probabilidade de detecção de comportamento corrupto por meio de monitoramento e fiscalização reforçados e rápida punição dos infratores. A abordagem seguinte apresenta como vantagem a responsabilização reforçada dos funcionários públicos por meio da promoção da boa governança e da adesão à transparência e aos padrões na condução dos negócios públicos. A terceira baseia-se em reformas econômicas que exploram as deficiências nas políticas e instituições econômicas. A simplificação do sistema tributário, a reforma na administração fiscal e alfandegária e as privatizações são exemplos de ações para combater a corrupção nessa última abordagem (ABED; DAVOODI, 2000).

Dessa feita, segue-se a metodologia proposta para a análise dos programas de governo do pleito eleitoral de 2018 para o cargo de presidente da República.

\section{Metodologia}

O presente trabalho consiste em uma pesquisa qualitativa, valendo-se das técnicas correlatas à análise de conteúdo, para investigar os planos de governo dos treze candidatos ao cargo de presidente da República Federativa do Brasil nas eleições 2018.

Por se tratar de uma pesquisa qualitativa, o processo de interpretação não é baseado em modelos estatísticos (STRAUSS; CORBIN, 2008). Os documentos foram extraídos do sítio eletrônico do Tribunal Superior Eleitoral (TSE) em 21 de setembro de 2018, data em que as candidaturas foram consideradas definitivas. A organização dos dados foi desenvolvida com o suporte do software Atlas. TI, em sua versão 7.5.16. Esse software foi, inicialmente, desenvolvido na Universidade Técnica de Berlim, Alemanha, dentro de um projeto multidisciplinar ocorrido no final da década de 1980, e permite a coleta de informações em fontes diversas e tipos distintos de documentos, como textos, áudio e vídeo (BANDEIRA-DE-MELLO, 2006; WALTER; BACH, 2015).

No que tange à análise de conteúdo, ela consiste na sistematização de pesquisa do conjunto de palavras, da tentativa de captar tendências textuais, que contam com exemplos dispersos, mas variados (ROCHA; DEUSDARÁ, 2005). Mozzato e Grzybovski (2011) relembram que esse conjunto de técnicas procura superar as incertezas e acrescer à compreensão dos dados coletados.

Discorre Bardin (1977, p. 95) que a análise de conteúdo atravessa três momentos: "1) a pré-análise; 2) a exploração do material; 3) o tratamento dos resultados, a inferência e a interpretação". Nesse sentido, a autora propõe uma leitura flutuante do conteúdo a ser analisado, visando um entendimento inicial ainda raso do assunto, no sentido de propor indicadores e categorias de análise. A partir da pré-análise, seguindo a nomenclatura do Atlas.TI, foram atribuídas duas famílias de códigos: "Identificação da Corrupção", relacionada à visão que os candidatos possuem sobre a existência de práticas corruptas no setor público, e "Combate à Corrupção", que aborda propostas para solucionar ilicitudes dessa natureza no plano federal. O Quadro 1, a seguir, aponta as famílias, os códigos e as palavras consideradas. 
Quadro 1 - Codificação

\begin{tabular}{|c|c|c|}
\hline Família & Código & Palavras-chave \\
\hline \multirow[t]{2}{*}{$\begin{array}{l}\text { Identificação da } \\
\text { corrupção }\end{array}$} & Destinada aos agentes & $\begin{array}{l}\text { Legado do PT; Corrompeu a Democracia; Toma lá-dá-cá, Forma Perniciosa, Aparelhamento } \\
\text { dos Ministérios; Desvios de Conduta; Grandes Grupos Econômicos; Grandes Construtoras; } \\
\text { Condutas Corruptas; Velha Representação Política; Corruptores; Interesses Escusos; } \\
\text { Instituições que Menos Confia }\end{array}$ \\
\hline & Destinada à estrutura & $\begin{array}{l}\text { Privilégios; Impunidade, Esperteza, Parte de Nossa Identidade, Desperdício; Prerrogativas } \\
\text { Indevidas; Esgotamento dos Mecanismos; Padrão Fisiológico; Crise Política; }\end{array}$ \\
\hline \multirow{4}{*}{$\begin{array}{l}\text { Combate à } \\
\text { corrupção }\end{array}$} & Mudança do marco legal & $\begin{array}{l}10 \text { Medidas Contra a Corrupção; Responsabilidade Partidária; Lei Anticorrupção; Reforma } \\
\text { Política; Lei da Ficha Limpa; Aperfeiçoar as Leis; Constituição; Tolerância Zero; Segurança } \\
\text { Jurídica; Mecanismos de Responsabilização; Simplificação das Leis; Poder Legislativo; } \\
\text { Criminalização }\end{array}$ \\
\hline & $\begin{array}{l}\text { Fortalecimento do } \\
\text { Judiciário }\end{array}$ & $\begin{array}{l}\text { Acordos de Leniência; Lava Jato; Aperfeiçoar Procedimentos; Combate Permanente à } \\
\text { Impunidade; Reforma do Sistema de Justiça; STF; Reforma dos Tribunais; Reforma do } \\
\text { Judiciário; Juridicamente; Lei Anticorrupção; Lei da Ficha Limpa; Investigações Barradas; } \\
\text { Poder Judiciário; Acordos Judiciais; Juízes }\end{array}$ \\
\hline & Reforma do Executivo & $\begin{array}{l}\text { Enxugar a Máquina Pública; Eliminar Privilégios; Eficiência na Gestão; Redução do } \\
\text { Congresso; Governo Eletrônico; Redução de Ministérios; Privatizações; Controladoria; } \\
\text { Compliance; Práticas regulatórias; Diálogo permanente; Idoneidade. Desperdício; Centrar a } \\
\text { Atuação do Estado; Poder Executivo }\end{array}$ \\
\hline & Controle Social & $\begin{array}{l}\text { Transparência; Controle social; Deliberação Direta; Democracia Direta; Ouvidoria; Governo } \\
\text { aberto; Iniciativa popular; Mobilização Popular }\end{array}$ \\
\hline
\end{tabular}

Fonte: Dados da pesquisa.

Considerando a família de "Identificação da Corrupção", a codificação buscou associar ao destinatário da crítica a responsabilidade pelas práticas delituosas. Assim, de um lado, encontram-se críticas destinadas aos agentes, isto é, àqueles a quem são atribuídos os crimes de corrupção, sejam essas acusações direcionadas a pessoas, partidos políticos ou grupos sociais e empresariais. Em outra vertente, apresentam-se as críticas destinadas à estrutura, em que os candidatos apontam inimigos sistemáticos, como o arcabouço legal, a estrutura político-partidária e, até mesmo, a formação social do Brasil como responsáveis pelos desvios de conduta.

No que remete aos códigos relacionados a propostas dos candidatos para combater à corrupção, foram identificadas quatro tipologias distintas. Em primeiro lugar, é reconhecido o código referente a mudanças na legislação vigente. Também foi constatada a incidência de propostas relacionadas ao fortalecimento do Poder Judiciário e sua reestruturação. Temos ainda a verificação de proposições dos candidatos que se associam com a reestruturação do Poder Executivo e os órgãos a ele subordinados. Por fim, o código que correlaciona a solução da corrupção a ações de controle do cidadão.

Nota-se que alguns termos e palavras se repetem em categorias de codificação distintas. Em primeiro lugar, porque existe a possibilidade de um mesmo trecho do programa representar mais de uma categoria. Além disso, cumpre destacar que uma mesma palavra pode ser utilizada em contextos diferentes, o que alteraria o conteúdo da sentença.

Partindo dessa fase inicial proposta pela metodologia, os dados foram tratados no software Atlas. TI considerando a busca pelas palavras-chave listadas no Quadro 1 nos documentos escritos de programa de governo do corpus de pesquisa. Na parametrização, foi considerada a ocorrência da palavra ou do termo dentro de um parágrafo. As ocorrências foram verificadas uma a uma, visando ao controle do sentido do texto e sua pertinência à categoria correlata. Nesse sentido, foram expurgados os conteúdos que consistiam em títulos de seção do documento e as aparições das palavras em contextos que não tinham correlação com a temática de corrupção. A seção a seguir apresenta os resultados, inferências e interpretação da pesquisa.

\section{Resultado e Discussão}

Considerada a metodologia proposta, o estudo busca atingir seu objetivo de compreender como a corrupção foi abordada nos programas de governo dos candidatos ao cargo de presidente da República Federativa do Brasil em 2018. Os programas de governo foram entregues pelos candidatos à presidência ao Tribunal Superior Eleitoral em agosto de 2018, entretanto uma das candidaturas desse pleito foi indeferida, ocorrendo uma substituição de chapa no decorrer do mês de setembro de 2018. Dessa forma, foi descartado o programa de governo do candidato impedido pela Justiça Eleitoral, ao mesmo tempo em que foi incluído o documento relativo ao candidato que o substituiu. Esses documentos foram lançados no software ATLAS.TI. A Tabela 1, a seguir, ilustra os documentos primários considerados neste estudo. 
Tabela 1 - Documentos primários

\begin{tabular}{llc}
\hline Candidato & Filiação partidária & Número de páginas \\
\hline Geraldo Alckmin & Partido da Social Democracia Brasileira (PSDB) & 9 \\
Álvaro Dias & Podemos (PODE) & 15 \\
João Amoedo & Partido Novo (NOVO) & 23 \\
Jair Bolsonaro & Partido Social Liberal (PSL) & 81 \\
Guilherme Boulos & Partido Socialismo e Liberdade (PSOL) & 228 \\
Cabo Daciolo & Patriota (PATRI) & 17 \\
Ciro Gomes & Partido da Democrático Trabalhista (PDT) & 62 \\
José Maria Eymael & Democracia Cristã (DC) & 9 \\
João Goulart Filho & Partido Pátria Livre (PPL) & 14 \\
Marina Silva & Rede Sustentabilidade (REDE) & 24 \\
Henrique Meirelles & Movimento Democrático Brasileiro (MDB) & 21 \\
Vera Lúcia & Partido da Causa Operária (PCO) & 5 \\
Fernando Haddad & Partido dos Trabalhadores (PT) & 61 \\
\hline
\end{tabular}

Fonte: Elaborada pelos autores.

É válido pontuar que não foi delimitado pela legislação eleitoral um tamanho mínimo ou máximo para os programas lançados pelos candidatos. Não foi encontrado um padrão no número de páginas do universo pesquisado. A média de páginas foi de 43,7 , tendo o plano de governo de Guilherme Boulos, do PSOL, maior extensão, com 228 páginas, enquanto o programa de Vera Lúcia, do PCO, foi o menos extenso, com apenas 5 páginas. Também não houve um padrão gráfico nos documentos primários da pesquisa, isto é, os documentos não guardavam um modelo semelhante de formatação, tamanho de letra, cores, figuras e outros elementos, sendo de livre escolha dos candidatos a forma de apresentação do conteúdo.

A teoria apresentada e a pré-análise levaram à formulação de uma associação entre os códigos e textos. Ele considera os códigos e possíveis temáticas apresentadas nas sentenças selecionadas. Nesse diapasão, a Figura 1 demonstra graficamente a correlação esperada entre os códigos e o texto.

Figura 1 - Correlação esperada entre os códigos e o texto
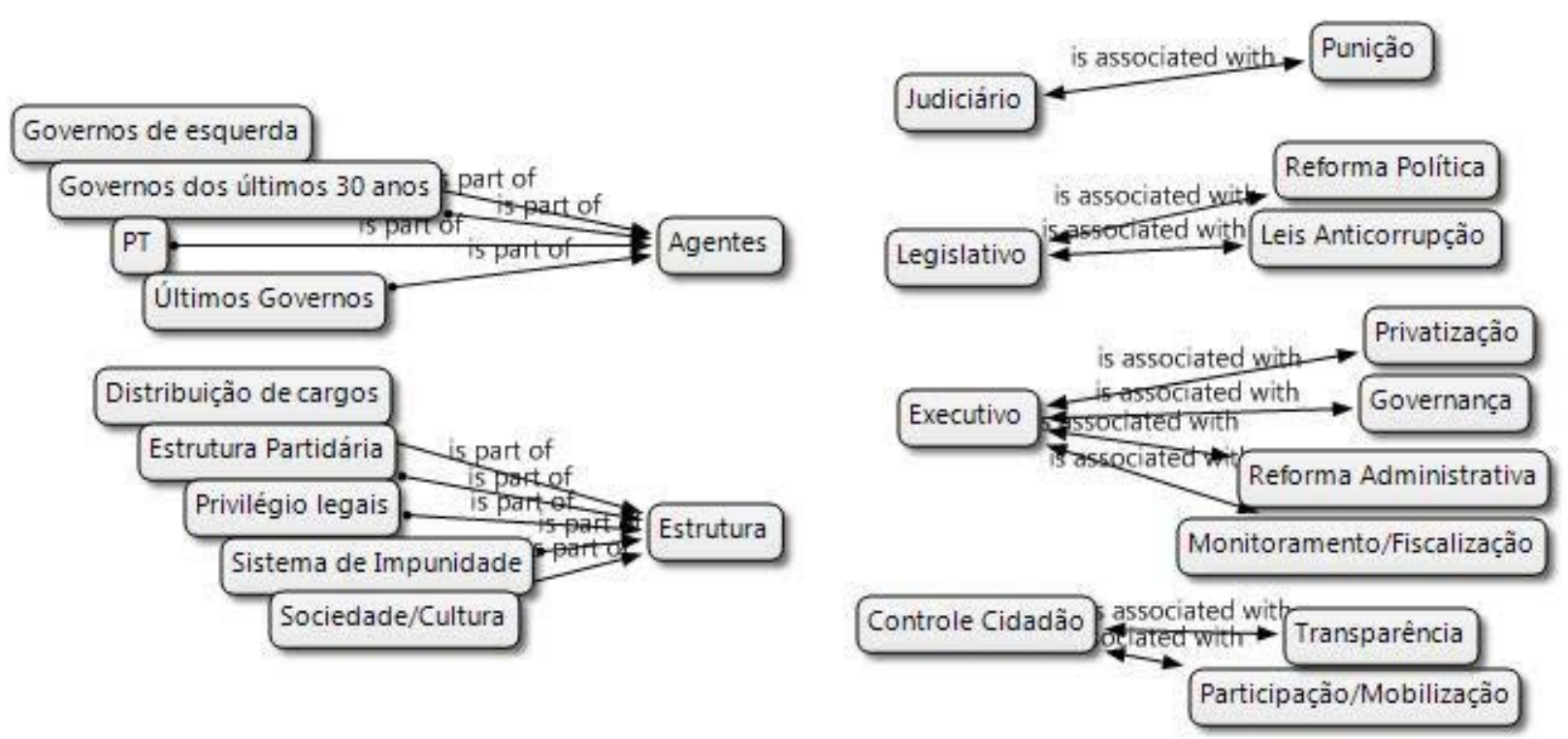

Fonte: Elaborada pelos autores.

A partir das palavraschave relacionadas no Quadro 1, fez-se a classificação do conteúdo, utilizando-se a função de autocodificação. Nessa funcionalidade, o programa apresenta a ocorrência de termos de busca relacionados aos códigos, facultando aos pesquisadores a possibilidade de validação de cada uma das codificações. Nesse sentido, a escolha desta pesquisa foi por abrir essa possibilidade de validação, haja vista, em primeiro lugar, a existência de significados diferentes para o uso de um mesmo vocábulo ou termo no contexto, alterando a percepção de sua relação com o tema corrupção. Além disso, alguns termos foram elencados em mais de uma categoria, uma vez que sua distinção ou repetição só poderia ser definida por um contexto de fala. 
As Tabelas 2 e 3, a seguir, apresentam a ocorrência de citações em cada programa de governo analisado, referentes à identificação da corrupção e ao combate à corrupção, respectivamente. Analisando de forma geral, os documentos com maior registro de ocorrências normalmente equivalem aos programas de governo com maior extensão em número de páginas. A leitura demonstrou que os programas mais extensos são, em geral, muito prolixos, expondo conceitos de forma repetitiva. Apenas dois dos treze candidatos se calaram em seus programas de governo quanto à questão da corrupção, o que demonstra o reconhecimento da relevância do tema para o público votante. Além disso, partindo para as famílias de códigos, é notável um número menor de ocorrências dos códigos relacionados à "Identificação da Corrupção", em vista da quantidade de aparições de termos relacionados ao "Combate à Corrupção".

Tabela 2 - Citações relativas à Identificação da Corrupção

\begin{tabular}{ccccc}
\hline Candidato & Partido & Agentes & Estrutura & $\begin{array}{c}\text { Identificação da } \\
\text { Corrupção }\end{array}$ \\
\hline Alckmin & PSDB & 0 & 0 & $\mathbf{0}$ \\
Alvaro Dias & PODE & 0 & 0 & $\mathbf{0}$ \\
Amoêdo & NOVO & 0 & 1 & $\mathbf{1}$ \\
Bolsonaro & PSL & 5 & 2 & $\mathbf{7}$ \\
Boulos & PSOL & 2 & 2 & $\mathbf{0}$ \\
Cabo Daciolo & PATRI & 0 & $\mathbf{1}$ \\
Ciro & PDT & 0 & 1 & $\mathbf{0}$ \\
Eymael & DC & 0 & 0 & $\mathbf{3}$ \\
Haddad & PT & 0 & 2 & $\mathbf{2}$ \\
João Goulart & PPL & 1 & 1 & $\mathbf{4}$ \\
Marina & REDE & 1 & 2 & $\mathbf{0}$ \\
Meirelles & MDB & 2 & 0 & $\mathbf{0}$ \\
Vera & PCO & 0 & 0 & $\mathbf{2 2}$ \\
\hline Total & & 0 & $\mathbf{1 1}$ & \\
\hline
\end{tabular}

Fonte: Elaborado pelos autores.

A Tabela 2 mostra que mais da metade dos candidatos sequer fazem menção de citações relacionadas à "Identificação da Corrupção", enquanto apenas dois dos candidatos não citam nada a respeito do assunto. Isso demonstra, em primeiro lugar, que o fato de haver corrupção é amplamente conhecido por boa parte da população votante, sendo desnecessário se estender sobre o assunto. Além disso, há que se considerar a possibilidade de alguns candidatos estarem associados a grupos que foram criticados pelos demais candidatos.

Quanto a essas críticas, cumpre enfatizar que, por vezes, elas estavam direcionadas a alguns grupos específicos, o que foi codificado como crítica aos agentes. De forma enfática, a crítica era destinada aos grupos político-partidários que assumiram o poder nos últimos anos no Brasil, ainda que dita de formas distintas, ou seja, ainda que os textos utilizassem vários termos diferentes, como "os governos dos últimos 30 anos", "a esquerda", "o PT", "os últimos governos", entre outros. Nota-se, portanto, que os candidatos trabalharam a ideia de um inimigo comum nesse assunto, considerando que os detentores do poder pudessem estar associados a escândalos de corrupção amplamente divulgados.

Em outras ocasiões, as citações mostram críticas ao sistema vigente, que poderia favorecer a existência da corrupção no Brasil. Nessa segunda modalidade de crítica, não há um consenso entre os candidatos quanto ao cerne do problema. A crítica foi destinada desde o sistema político-eleitoral até as questões de formação social do brasileiro, passando por aspectos legais relacionados aos privilégios e prerrogativas que algumas classes do serviço público possuem. Logo após, apresenta-se a Tabela 3, que trata das citações encontradas nos textos que tratam do "Combate à Corrupção". 
Tabela 3 - Citações relativas ao Combate à Corrupção

\begin{tabular}{|c|c|c|c|c|c|}
\hline Candidato & Controle cidadão & Executivo & Judiciário & Legislativo & $\begin{array}{l}\text { Combate à } \\
\text { Corrupção }\end{array}$ \\
\hline Alckmin & 1 & 4 & 0 & 3 & 8 \\
\hline Alvaro Dias & 1 & 2 & 1 & 4 & 8 \\
\hline Amoêdo & 4 & 4 & 1 & 3 & 12 \\
\hline Bolsonaro & 2 & 1 & 1 & 2 & 6 \\
\hline Boulos & 13 & 2 & 4 & 4 & 23 \\
\hline Cabo Daciolo & 1 & 0 & 0 & 0 & 1 \\
\hline Ciro & 6 & 2 & 2 & 2 & 12 \\
\hline Eymael & 1 & 1 & 0 & 0 & 2 \\
\hline Haddad & 8 & 0 & 8 & 3 & 19 \\
\hline João Goulart & 0 & 0 & 1 & 1 & 2 \\
\hline Marina & 9 & 3 & 0 & 2 & 14 \\
\hline Meirelles & 0 & 0 & 0 & 0 & 0 \\
\hline Vera & 0 & 0 & 0 & 0 & 0 \\
\hline Total & 46 & 19 & 18 & 24 & 107 \\
\hline
\end{tabular}

Fonte: Elaborado pelos autores.

Prosseguindo com a análise, destaca-se a codificação referente ao "Combate à Corrupção". É importante afirmar que todos os candidatos possuem citações nessa família de codificações, exceto dois candidatos (Vera Lúcia e Henrique Meirelles) que não pontuaram nenhuma questão sobre a corrupção em seus programas de governo. Curiosamente, ainda que o material analisado consistisse de programas e planos para postulantes de um cargo no Poder Executivo, esse tipo de solução não foi identificado com muita frequência nos planos de governo. Concomitantemente, fica explícito o enfoque no Controle Cidadão como solução para o problema da corrupção.

As propostas relacionadas à atuação do Poder Executivo, como já dito, não foram as de maior frequência nesta análise, embora esteja presente em oito dos treze documentos de intenção. Entre as propostas, alguns candidatos defendem que a diminuição do escopo de atividades estatais e a consequente privatização de alguns órgãos. Por outro lado, uma Reforma Administrativa, com extinção de ministérios, cargos de indicação política e políticas de austeridade, é louvada nos programas de governo que desenvolveram propostas de responsabilidade do Executivo. Além disso, os programas exaltam a necessidade de uma governança mais eficiente como meio de garantir a otimização da alocação dos recursos públicos e inibir os atos de corrupção.

Esmiuçando as propostas que visam alterar a legislação vigente no campo da corrupção, existe grande entonação no sentido de uma reforma política. Nesse sentido, a reforma proposta apresenta aspectos distintos para os candidatos. Existem propostas que caminham para a diminuição de cadeiras nas casas legislativas, outras relacionadas à mudança da forma de escolha do eleitor e, até mesmo, uma possível dispensa de filiação partidária obrigatória para candidaturas, coexistindo ainda o debate quanto ao financiamento de campanhas eleitorais.

Outro ponto relevante reside na simplificação das leis, enfatizada pelo termo desburocratização, de modo que se torne mais simples agir dentro da lei no país. Além disso, muitas propostas vão no sentido de aumentar a punição para os corruptos. Por algumas vezes, os candidatos retomaram as 10 Medidas Contra a Corrupção, documento elaborado pelo Ministério Público Federal, que, com apoio maciço da população, foi levado ao Congresso como uma proposta de lei de iniciativa popular, mas sem prosperar no certame legislativo.

Passando ao ponto das propostas que estão mais ligadas ao Poder Judiciário, nota-se uma grande concentração das ocorrências de códigos em apenas dois documentos: os programas de Fernando Haddad e de Guilherme Boulos. Esses programas recomendaram alterações que visavam maior controle sobre as ações do Judiciário. Dessa feita, os dois programas sugerem mandato temporário em Cortes Superiores e a instituição de mecanismos de controle social e de maior transparência nas decisões judiciais. Isso mostra, por parte desses candidatos, maior desconfiança nas ações da Justiça.

Por outro lado, os demais candidatos que perpassam pela questão mostraram a necessidade de defender a neutralidade da Justiça. Assim, foi aventada a defesa da Operação "Lava Jato" e de outras operações de investigação da corrupção. Além disso, alguns dos postulantes ao cargo de presidente discorreram sobre o fim de privilégios, no sentido de manter a neutralidade da Justiça. Por fim, são defendidos instrumentos de negociação para delação e acordo de leniência, que poderiam trazer ganhos de eficiência sobre o processo investigativo.

Finalmente, cabe destacar a codificação que se relaciona ao Controle Cidadão. É notável um adensamento de propostas nesse sentido, sendo citado por dez dos treze candidatos. As propostas colocadas trazem com muita ênfase o 
termo transparência. Existe a crença de que a divulgação de mais informações poderia inibir o comportamento corrupto, o que está também amparado pela teoria. No entanto carece de mais esclarecimentos quanto ao tipo de informação que seria disponibilizada nesses governos transparentes. Não existe uma definição por parte dos candidatos quanto ao nível de detalhamento de informações que estariam ao alcance do cidadão comum. Apesar disso, espera-se um aumento da quantidade e qualidade de dados divulgados pelo governo em diversas áreas, com destaque para a previdência social, programas assistenciais, obras e compras públicas, além do uso do fundo partidário.

Ao mesmo tempo, nota-se uma convergência que essa disponibilização de dados seria feita no ambiente virtual, pois os candidatos normalmente fazem menção a um governo eletrônico. Apesar de não haver um detalhamento nesse sentido, é provável que tais medidas fossem feitas por meio de portais na internet e aplicativos para dispositivos móveis. Quanto ao governo eletrônico, valoriza-se a integração de sistemas de informação, tanto no que tange às bases de dados dos distintos órgãos do próprio governo federal quanto em sua integração com sistemas estaduais e municipais. Essa transparência esperada é passível de aplicação aos processos decisórios dentro da Administração Pública, como escolha de fornecedores, de membros do alto escalão governamental, de projetos e soluções para o setor público.

Ainda assim, não se pode determinar políticas de combate à corrupção relacionadas ao Controle Cidadão baseado apenas no fato de trazer mais informações à sociedade. Nesse diapasão, há que se trabalhar a questão do incremento da participação do cidadão nas decisões de governo. Tais iniciativas estão propostas em menor número nos documentos primários considerados nesta pesquisa. Para estimular a participação cidadã, uma medida encontrada em alguns programas se refere à ampliação de ouvidorias ou sua extensão a algumas instâncias que não contam com essa atuação no presente. Outras proposições vão no sentido de fortalecer o papel dos conselhos populares, estendendo seu papel de fiscalização e controle da corrupção. Ainda, dentro de um sentido amplo de participação, colocam-se medidas de simplificação para a proposição de leis de iniciativa popular.

Portanto, finalizada a análise da codificação para o conjunto de documentos primários em questão, as considerações finais apresentam a síntese do estudo proposto.

\section{Considerações Finais}

O presente estudo propôs a compreensão de como a corrupção foi abordada nos programas de governo dos candidatos ao cargo de Presidente da República do Brasil em 2018. Para tanto, foram analisados todos os programas de governo lançados no sítio eletrônico do Tribunal Superior Eleitoral, de candidatos que não sofreram impugnação de suas candidaturas. Considerando tal objetivo, construiu-se um referencial teórico que fosse esclarecedor quanto às temáticas correlatas. Foi utilizada a metodologia de análise de conteúdo para responder à pergunta de pesquisa. Apenas dois dos treze candidatos não fizeram nenhuma menção ao tema proposto, o que demonstra a relevância do debate no contexto apresentado.

O tema corrupção foi dividido em duas grandes famílias de códigos. A primeira foi denominada "Identificação da Corrupção", que aponta para a existência da corrupção, suas mazelas e possíveis responsáveis. A segunda foi nomeada "Combate à Corrupção", que trabalhou mais efetivamente as propostas que os candidatos apresentaram nos documentos para resolver essa questão em sua esfera de atuação. As codificações relacionadas ao combate à corrupção obtiveram maior espaço dentro dos documentos analisados.

No que tange à identificação da corrupção, quando a corrupção apontada como originada dos agentes, os candidatos normalmente convergem no sentido de acusar os últimos governos como responsáveis pelo problema. Este apontamento fica evidenciado, embora se use termos diversos, como os últimos governos, os governos dos últimos 30 anos ou citações diretas aos partidos que dominaram o cenário político nas últimas décadas. No momento em que essa crítica é destinada à estrutura, existe uma difusão no destinatário da crítica, que perpassa desde o sistema político atual em diversos aspectos até à formação social brasileira, como responsável pelo brasileiro sempre querer levar vantagem.

Ao trabalhar o combate à corrupção, observou-se uma forte ênfase no controle cidadão dos processos do Estado. A análise encontrou grande ocorrência do termo transparência. Essa transparência está fortemente associada aos dados governamentais de compras públicas, gastos públicos, previdência social e programas de assistência social. Em um segundo plano, a transparência também teria correlação com os processos decisórios na esfera federal, como seleção para cargos de livre nomeação e a escolha de projetos e fornecedores. Em menor grau, também existe o interesse dos candidatos em fortalecer políticas de participação direta ou de representantes da sociedade no sentido de fiscalizar o poder público.

Ainda dentro do grupo de códigos relacionados ao combate à corrupção, nota-se uma concordância no discurso dos candidatos quanto a necessidade de reforma do sistema político. Entretanto, as prioridades dessa reforma são distintas dentro do universo pesquisado. A redução do escopo de atividades consideradas do Estado também é vista como forma de coibir a corrupção. As propostas também são concordantes no sentido da necessidade de maior punição aos corruptores, sendo necessária uma revisão da legislação atual. A base principal dessa reformulação seria o documento criado pelo Ministério Público Federal denominado "10 Medidas contra a Corrupção".

Em última análise, a pesquisa evidencia que, embora a temática corrupção tenha ganhado relevância no debate nacional nos últimos anos, ainda não existe um consenso claro no campo político quanto às medidas de combate 
ao comportamento corrupto no setor público. Como destaque, o candidato vencedor do pleito apresentou em seu programa um número maior de apontamentos a agentes corruptos e propôs mudanças em todos os códigos da pesquisa relacionados ao combate à corrupção. Entretanto não se pode decretar sua vitória eleitoral apenas pelos debates relacionados à temática abordada pelo estudo.

É válido destacar que os documentos pesquisados possuem importância ao apresentar as principais ideias que os candidatos ao cargo possuem para assumir o cargo. Os planos de governo são utilizados por várias vezes nas propagandas eleitorais, em debates e durante a cobertura jornalística das eleições. Ainda assim, os planos de governo não possuem caráter contratual, sendo possível que um eventual governo não siga o plano apresentado durante o período eleitoral.

Por fim, admite-se, naturalmente, a necessidade de novos estudos que ampliem a compreensão sobre a questão colocada, haja vista sua delimitação conveniente para fins de análise. Além dos planos de governo, outros materiais podem incrementar em estudos futuros a compreensão a respeito das propostas para o combate à corrupção, como a cobertura midiática do pleito eleitoral, a participação em debates e as mídias sociais que foram mais amplamente utilizadas na campanha eleitoral de 2018. Mesmo os planos de governo podem trazer respostas para outras questões governamentais envolvendo assuntos de grande relevância no cenário atual, como segurança pública, saúde e educação. O mesmo método empregado pode auxiliar na compreensão de fenômenos sociais de outras realidades.

\section{Referências}

ABED, M. G. T.; DAVOODI, M. H. R. Corruption, structural reforms, and economic performance in the transition economies. [S. I.:s.n.]. 2000. (International Monetary Fund Working Paper, 00/132).

ABRAMO, C. W. Percepções pantanosas: a dificuldade de medir a corrupção. Novos Estudos CEBRAP, São Paulo, v. 73, n. 2, p. 33-37, 2005.

ANDREWS, C. W. Implicações teóricas do novo institucionalismo: uma abordagem habermasiana. Dados - Revista de Ciências Sociais, Rio de Janeiro, v. 48, n. 2, p. 271-299, 2005.

ARAÚJO, U. P.. Relação agência e estrutura em redes colaborativas: uma análise do consórcio brasileiro de pesquisa e desenvolvimento do café. 2008. Tese (Doutorado em Administração) - Universidade Federal de Lavras, Lavras, 2008.

BANDEIRA-DE-MELLO, R. Softwares em pesquisa qualitativa. In: GODOI, C. K.; BANDEIRA-DE-MELLO, R.; SILVA, A. B. (org.). Pesquisa qualitativa em estudos organizacionais: paradigmas, estratégias e métodos. São Paulo: Saraiva, 2006.

BARDIN, L. Análise de conteúdo. Lisboa: Edições 70, 1977.

BRASIL. Lei $\mathbf{n}^{\circ}$. 12.527, de 18 de novembro de 2011. Regula o acesso a informações e dá outras providências. Brasília, 2011. Link. Acesso em: 14 nov. 2018.

BREI, Z. A. A corrupção: causas, consequências e soluções para o problema. Revista de Administração Pública, Rio de Janeiro, v. 30, n. 3, p. 103-115, 1996.

BRONZO, M.; HONÓRIO, L. O institucionalismo e a abordagem das interações estratégicas da firma. Revista de Administração de Empresas, [S. I.], v. 4, n. 1, 2005.

CARVALHO, C. A.; VIEIRA, M. M. F.; GOULART, S. A trajetória conservadora da teoria institucional. Revista de Administração Pública, Rio de Janeiro, v. 39, n. 4, p. 849-874, 2005.

CHANLAT, J. F. L'analyse sociologique des organisations: un regard sur la production anglo-saxonne contemporaine (1970-1988). Sociologie du travail, [S. I.], n. 3, p. 381-400, 1989.

DIMAGGIO, P. J.; POWELL, W.W. The iron cage revisited: institutional isomorphism and collective rationality in organizational fields. American Sociologian Review, [S. I.], v. 48, n. 2, p. 147-160, 1983.

FILGUEIRAS, F. Marcos teóricos para o estudo da corrupção. In: AVRITZER, L.; BIGNOTTO, N.; GUIMARÃES, J.; STARLING, H. M. (org.). Corrupção: ensaios e crítica. Belo Horizonte: UFMG, 2008. 
FREITAS JÚNIOR, L. R.; MEDEIROS, C. R. O.. Estratégias de racionalização da corrupção nas organizações: uma análise das declarações de acusados em casos de corrupção no Brasil. Revista de Ciências da Administração, [S. I.], v. 5, n. 50, p. 8-23, abr. 2018.

GROSSI, G.; PIANEZZI, D. The new public corruption: old questions for new challenges. Accounting Forum, [S. I.], v. 42 , n. 1, p. 86-101, 2016.

HALL, P. A.; TAYLOR, R. C. Political science and the three new institutionalisms. Political Studies, [S. I.], v. 44, n. 5, p. 936-957, 1996.

HAWLEY, A. Human ecology. In: SILLS, D. L. (ed.). International encyclopedia of the social sciences, New York: Macmillan, p. 328-337, 1968.

HODGSON, G. M. Economia e instituições: manifesto por uma economia institucionalista moderna. Oeiras: Celta, 1994.

HUNTINGTON, S. P. A ordem política nas sociedades em mudança. São Paulo: Ed. USP. 1975.

JOHNSTON, M. Agentes públicos, interesses particulares e democracia sustentável: Quando política e corrupção se unem. In: ELLIOT, K. A. (org.). A corrupção e a economia mundial. Brasília: Editora Universidade de Brasília, 2002.

KOTERA, G.; OKADA, K.; SAMRETH, S. Government size, democracy, and corruption: an empirical investigation. Economic Modelling, [S. I.], v. 29, n. 6, p. 2340-2348, 2012.

LOPES, Herton Castiglioni. A corrupção no estado: uma análise histórica e institucionalista a partir das contribuições de Raymundo Faoro e Sérgio Buarque de Holanda. Gestão Pública: práticas e desafios, [S. I.], v. 5, n. 2, 2014.

MATIAS-PEREIRA, J. Democracia, transparência e corrupção no Brasil. GIGAPP Estudios/ Working Papers, [S. I.], n. 92, p. 263-289, 2018.

MOZZATO, A. R; GRZYBOVSKI, D. Análise de conteúdo como técnica de análise de dados qualitativos no campo da administração: potencial e desafios. Revista de Administração Contemporânea, [S. I.], v. 15, n. 4, p. 731-747, 2011.

OLIVEIRA JÚNIOR, T.; COSTA, F.; MENDES, A. Perspectivas teóricas da corrupção no Brasil: características, limites e alternativas. In: ENCONTRO DE ADMINISTRAÇÃO PÚBLICA E GOVERNANÇA, 6., Belo Horizonte. Anais [...]. Belo Horizonte: ANPAD, 2014.

QUIRINO, F. G. S.; RIBEIRO, L. M. P. ; ASSIS, L. B.; SILVA, A. F.. 200 million in action: the cordial man and the film analysis of World Cup television advertisements. Soccer \& Society, [S. I.], v. 21, n. 2 p. 180-195, 2018.

ROCHA, D.; DEUSDARÁ, B. Análise de conteúdo e análise do discurso: aproximações e afastamentos na (re) construção de uma trajetória. Revista Alea, [S. I.], v. 7, n. 2, p. 305-322, 2005.

ROSA, A. R. A imagina(organiza)ção surrealista: rompendo a gaiola de ferro dos estudos organizacionais. Cadernos EBAPE.BR, Rio de Janeiro, v. 6, n. 1, p. 1-16, 2008.

ROSE-ACKERMAN, S. Corruption and government: causes, consequences and reform. Cambridge: Cambridge University Press, 1999.

SARGIACOMO, M.; IANNI, L.; D'ANDREAMATTEO, A.; SERVALLI, S. Accounting and the fight against corruption in Italian government procurement: a longitudinal critical analysis (1992-2014). Critical Perspectives Accounting, [S. I.], v. 28, p. 89-96, 2015.

SCOTT, W. R. Institutions and organizations. London: Sage, 1995. (Foundations for Organizational Science).

SHLEIFER, A.; VISHNY, R. W. Corruption. The Quarterly Journal of Economics, [S. I.], v. 108, n. 3, p. 599-617, 1993.

SILVA, M. Corrupção: tentativa de uma definição funcional. Revista de Administração Pública, [S. I.], v. 28, n. 1, p. 18-23, 1994. 
STRAUSS, A.; CORBIN, J. Pesquisa qualitativa: técnicas e procedimentos para o desenvolvimento de teoria fundamentada. Porto Alegre: Artmed, 2008.

TRANSPARENCY INTERNATIONAL. Corruption perceptions index 2019. Link. Acesso em: 27 jan. 2020.

WALTER, S. A.; BACH, T. M. Adeus papel, marca-textos, tesoura e cola: inovando o processo de análise de conteúdo por meio do atlas.ti. Administração: Ensino e Pesquisa, [S. I.], v. 16, n. 2, p. 275-308, 2015.

WEBER, M. Economy and society: an outline of interpretive sociology. Berkeley: University of California Press, 1968.

ZUCKER, L. G. Institutional theories of organization. Annual Review of Sociology, [S. I.], v. 13, n. 1, p. 443-464, 1987.

\section{Contato:}

Fernando Gustavo da Silva Quirino

E-mail: fernandogquirino@gmail.com

Lívia Maria de Pádua Ribeiro

E-mail: livia.padua2014@gmail.com

Amanda Fontes Silva

E-mail: amandaf_silva@hotmail.com

Gabriel Augusto de Carvalho

E-mail: ga09carvalho@gmail.com 